\title{
VANILLA RIVASII (ORCHIDACEAE), A NEW SPECIES FROM THE COLOMBIAN PACIFIC REGION
}

\author{
Francisco Molineros-Hurtado, ${ }^{1,2}$, Robert Tulio González Mina ${ }^{1,2}$, \\ Nicola S. Flanagan ${ }^{1,3} \&$ J. Tupac Otero ${ }^{1,4,5}$ \\ ${ }^{1}$ Grupo de Investigación en Orquídeas, y Ecología y Sistemática Vegetal \\ ${ }^{2}$ Programa de Agronomía, Universidad del Pacifico, Avenida Simón Bolívar 54ª-10, \\ Buenaventura, Colombia \\ ${ }^{3}$ Programa de Biología, Pontificia Universidad Javeriana, Cali, Colombia \\ ${ }^{4}$ Departamento de Ciencias Biológicas, Universidad Nacional de Colombia, \\ Sede Palmira, Palmira, Colombia \\ ${ }^{5}$ Instituto de Estudios Ambientales IDEA, Palmira. Universidad Nacional de Colombia, \\ Sede Palmira, Palmira, Colombia
}

\begin{abstract}
AвSTRACt. We describe a new species of fragrant Vanilla from the Chocó biogeographic region of Western Colombia, named Vanilla rivasii sp. nov. in honor of the local farmer who drew it to our attention. This species is related to the Vanilla hostmannii group, also containing $V$. dressleri, V. ruiziana and $V$. cribbiana, with which it shares flower traits such as the showy, yellowish flower with thickened longitudinal venation in the lip apex. Vanilla rivasii is characterised by possessing: a long racemose inflorescence up to $60 \mathrm{~cm}$ in length, carrying up to 150 yellow flowers, with two to four open simultaneously; a trilobed labellum with a conspicuously bi-lobulated central lobe; and basally fused lateral sepals. Vanilla rivasii can be distinguished from the most morphologically-similar species, V. cribbiana and V. hostmannii, by the number of veins in the cushion-like structure of the lip and the larger size and higher number of flowers per inflorescence. This discovery highlights northern South America as a centre of diversity for this economically-important genus, and underlines the need for further botanical exploration in the highly biodiverse region of the Chocó.
\end{abstract}

KEY words: Orchidaceae, Vanilla, fragrant clade, V. rivasii, Buenaventura, Chocó, Colombia

Vanilla Plumier ex Miller, a pan-tropical genus within the Orchidaceae, contains over 100 species, with several species, principally Vanilla planifolia Andr., being of economic importance in the food and cosmetics industries. These commercially-valuable species form part of the so-called fragrant clade: Vanilla subgenus Xanata Soto Arenas \& Cribb, comprising species producing fragrant fruits, and which are naturally distributed exclusively within the neo-tropics (Soto-Arenas \& Cribb 2010). While $V$. planifolia is the predominant commercial species, other fragrant Vanilla species are of interest for their potential in vanilla breeding programmes. However, the diversity and biology of this clade has been poorly studied.
In a recent generic review, the existence of undescribed neotropical species became evident (Soto-Arenas \& Dressler 2010), with a new species, Vanilla espondae Soto Arenas, described from the Magdalena river valley of Colombia (Soto-Arenas 2010). Vanilla is a taxonomically-challenging genus, with our understanding of the diversity and biology of these species hindered by plants being rare and hyperdispersed in their native forest habitat. Furthermore, flowering is infrequent, and a large proportion of herbaria material is sterile.

In Colombia, 11 Vanilla species have been reported to date (Table 1). The genus Vanilla reaches its greatest diversity in South America, and, given the rare distributions of these plants, the inadequate nature

* This paper was prepared in the framework of the celebration of Lankester Botanical Garden's $40^{\text {th }}$ anniversary. 
TABLE 1. List of Vanilla species reported for Colombia (Soto Arenas \& Cribb 2010).

\begin{tabular}{l|l|c}
\hline Species & Reference & Year \\
\hline Vanilla calyculata Schltr & Repert. Spec. Nov. Regni Veg. Beih. 7: 42-43 & 1920 \\
\hline Vanilla columbiana Rolfe & J. Linn. Soc., Bot. 32: 468 & 1896 \\
\hline Vanilla dressleri Soto-Arenas & Lankesteriana 9(3): 303-305, f. 5 & 2010 \\
\hline Vanilla espondae Soto-Arenas & Lankesteriana 9(3): 281-284, f. 1-2 & 2010 \\
\hline Vanilla hostmannii Rolfe & J. Linn. Soc., Bot. 32: 462 & 1896 \\
\hline Vanilla odorata C. Presl & Reliq. Haenk. 1(2): 101 & 1827 \\
\hline Vanilla palmarum (Salzm. ex Lindl.) Lindl. & Gen. Sp. Orchid. Pl. 436 & 1840 \\
\hline Vanilla pompona Schiede & Linnaea 4: 573-574 & 1829 \\
\hline Vanilla ribeiroi Hoehne & Comm. Lin. Telegr., Bot. 1: 28 & 1910 \\
\hline Vanilla sprucei Rolfe & J. Linn. Soc., Bot. 32: 461 & 1896 \\
\hline Vanilla trigonocarpa Hoehne & Arq. Bot. Estado São Paulo 1(6): 126-127, t. 139 & 1944 \\
\hline
\end{tabular}

of most herbarium specimens and the poor botanical records of lowland areas, it is likely more species will be reported for the country, both described and undescribed.

Here we describe a new Vanilla species native to the Chocó biogeographic region of the Pacific Coast of Colombia. This region has the highest documented plant diversity (Faber-Langendoen \& Gentry 1991), and is still relatively under-explored botanically. The region retains more than $50 \%$ of its original vegetation cover, and continued taxonomic description of the diversity of the region is essential in order to establish conservation priorities.

Vanilla rivasii Molineros, Rob.González, Flanagan \& J.T.Otero, sp. nov.

TYPE: Colombia, Valle del Cauca, Buenaventura, Sendero El Paraíso, cultivated by A. Rivas, R. T. Gonzalez 1118 (holotype, CUVC). Figures 1-2.

Hemi-epiphytic herb. Stems dark green, 6.8-8.0 $\mathrm{mm}$ thick, terete, smooth, the internodes $8.0-9.3 \mathrm{~cm}$ long. Young aerial roots greenish to greyish, subterete to flattened, $4.2 \mathrm{~mm}$ thick. Leaf shortly petiolate, the petiole $c a .10 \mathrm{~mm}$ long, blade oblanceolate, acuminate, the apex incurved, base subobtuse, the basal margin revolute, subcoriaceous, pale green with a central concavity, $16.5-24.6 \times 4.0-5.5 \mathrm{~cm}$. Inflorescence terminal, sometimes lateral with pale green rachis of $12-40 \mathrm{~cm}$ in length and $0.7 \mathrm{~cm}$ in thickness with white dots in the epidermis, a shortly pedunculate raceme, the rachis congested, with up to 150 flowers, with bracts distant up to $6 \mathrm{~mm}$. Bracts pale green, basal ones alternate distichal. Distal bracts ovate and concave, 3-4 $\times 5 \mathrm{~mm}$. Ovary subterete to sub-trigonous, curved, pale green with white base and white dots in the epidemis, $45-55 \mathrm{~mm}$ length and $4.5 \mathrm{~mm}$ in diameter, white in the base and pale green in the rest. Flowers ephemeral with 2-4 open simultaneously, conspicuous with buds pale yellow at base, apex green, 10-12 cm diameter when spread out, aroma of rose and clover flowers; sepals yellowish green outer, whitish yellow inside, basal surface of the lip yellow, mid lobe and throat yellow lined dark yellow-ochre; the segments spreading, strong rose fragrance. Dorsal sepal yellowish green, deeply recurved, long-lanceolate, narrow at the base, apex sub-acute and sub-calyptrate, with 13 veins, of equal length to lateral sepals, $68 \times 8-10 \mathrm{~mm}$. Lateral sepals directed downwards, long-lanceolate, subacute, base long attenuate, lateral sepals fused in the proximal third of the length; with 13-14 veins, very smooth, $67 \times 8-11 \mathrm{~mm}$. Petals pale yellow to cream, slightly recurved at the apex, narrowly elliptic-oblanceolate, obtuse, concave, narrower than the sepals, longitudinally keeled on the abaxial surface, the keel broad and conspicuous, 7-8 veins, $68 \times 9 \mathrm{~mm}$. Lip showy, $66 \times 35 \mathrm{~mm}$ forming a long 


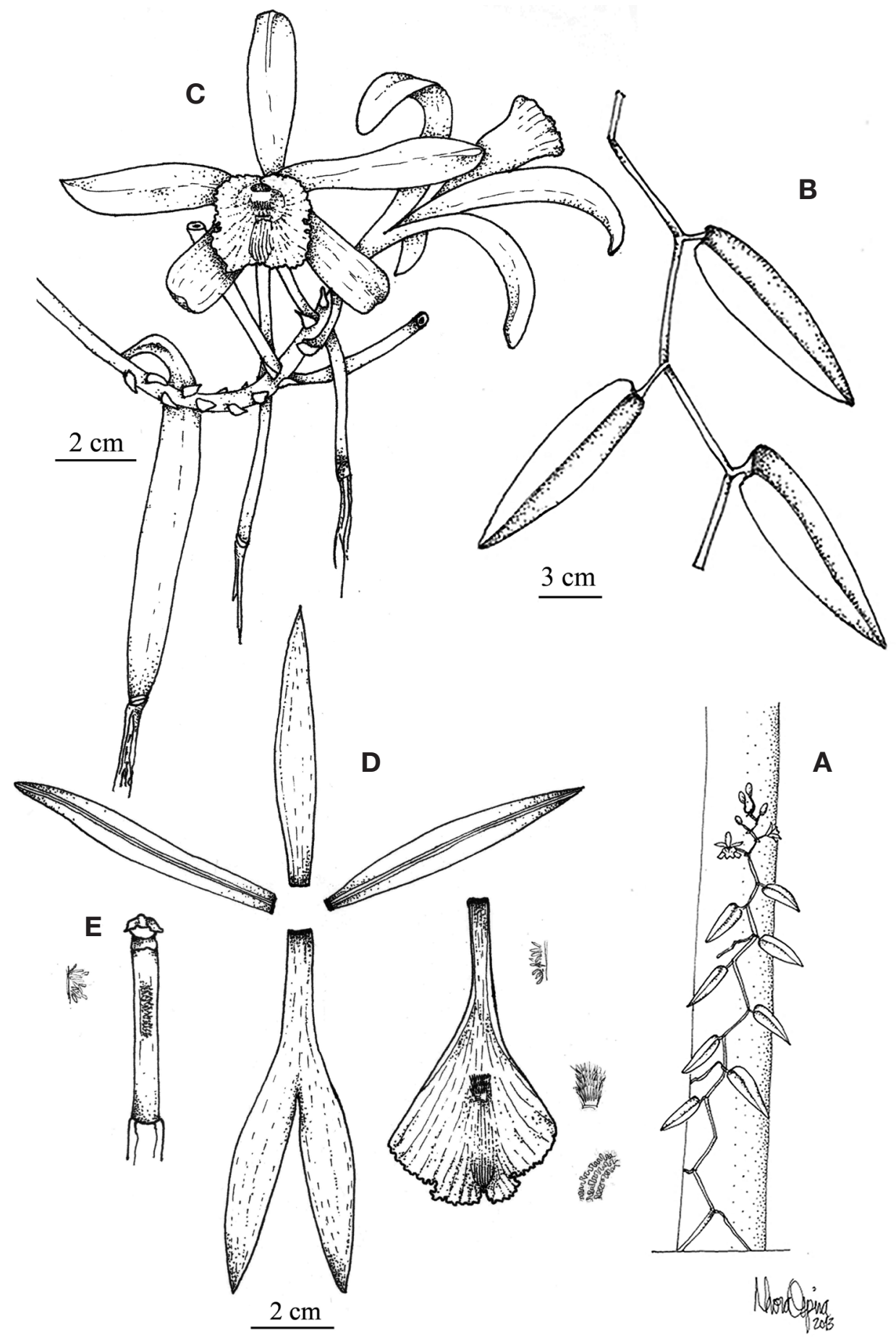

Figure 1. Vanilla rivasii Molineros, Rob.González, Flanagan \& J.T.Otero. A - Habit. B - Portion of the stem with leaves and root. C - Inflorescence with flowers and fruits. D - Dissected perianth, with details of the indumenta. E - Column, ventral view, with detail of the ventarl indumentum. Prepared from the holotype by Robert Tulio Gonzalez. Drawing by Nhora Helena Ospina Calderón. 


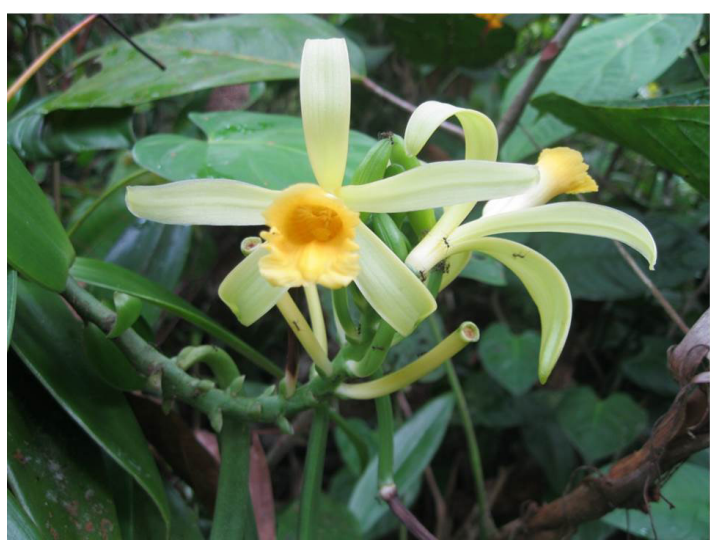

FIgURE 2. Vanilla rivasii, photograph of the flower in situ. Photo by F. Molineros-Hurtado.

tube, marginally fused to the column at least 40-42 $\mathrm{mm}$, with 30 veins; when spread out trilobed with the midlobe oblong, bilobulated, the lateral lobes well defined with rounded shoulders, overlapping above the column, oblong-triangular to sub-square, tapering at apex, with thickened axial cushion near the lip apex ca. $6 \times 23 \mathrm{~mm}$ with 7-8 thickened keels with papilose texture extended to the lateral lobes. The margin of the lip is sub-entire and flabellate; slightly verrucose at the base with brownish papillae, the apex somewhat narrowed and forming a cushion, the penicillate callus $4.5 \times 6.0 \mathrm{~mm}$ covered by 4 yellow showy lacerate structures of scales thickened in the distal portion, separated $44 \mathrm{~mm}$ from the lip base. Column subterete, elongated 45.0-49.0 $\times 2.6$ $\mathrm{mm}$, yellow whitish, with brownish tricomes in the distal ventral part; membranous wings $5.3 \mathrm{~mm}$; bilobed stigma with rectangular emergent lobes, 1.2 $\times 1.1 \mathrm{~mm}$. Anther versatile, ovate, $3 \times 2.6 \mathrm{~mm}$. Fruits elongated, pale green, subtriangular with white dots in the epidermis. 130-180 $\times 11 \mathrm{~mm}$, dehiscent when mature into two valves, with a strong vanilla aroma detectable over more than $200 \mathrm{~m}$.

Paratype: Colombia, Valle del Cauca, Buenaventura, Bahía Málaga. N. H. Ospina 466 (CUVC).

Other ReCords: Colombia, Buenaventura, F. G. Lehmann H.K.1185 (K, fruit!).

Distribution: Known only from the Pacific coastal region in the Valle del Cauca, and Chocó Departments, Colombia. The species has been observed occurring naturally in the wild in small isolated populations, mainly in regenerating secondary growth forest. Known populations comprise between one and twelve apparently separate plants. The largest population of twelve plants occurs over an area of $25 \mathrm{Ha}$. Localities have been identified up to $300 \mathrm{~km}$ apart. The association with secondary forest may be a consequence of sampling bias, as most exploration has been conducted close to populated regions. It is likely that, with further exploration of the Colombia Pacific region, particularly away from settlements along the coast, more populations will be found. The known localities will not be mentioned explicitly so as to protect the small populations of this species from the threat of collection from the wild.

Phenology: No clear seasonality has been observed. Initiation of flowering has been observed in the month of January, corresponding with a dryer climatic period in the region. However flowering has continued until April, June, July and September, resulting in inflorescences of up to 150 flowers. Natural fertilization has been observed of 6-18\% of flowers in an inflorescence.

Eponymy: This species is dedicated to Luis Álvaro Rivas, a local farmer committed to sustainable agricultural practices and biodiversity preservation.

The type specimen consists of the collection R.T. Gonzalez 1118 from Buenaventura, and N. H. Ospina 466 from Bahia Malaga, with pictures taken by $\mathrm{F}$. Molineros-Hurtado.

Vanilla rivasii Molineros-Hurtado, González, Flanagan \& Otero belongs within Vanilla subgenus Xanata. Vanilla rivasii has affinity to the $V$. hostmannii group, possessing the thickened veins in the lip apex and the distichous arrangement of the basal bracts of the inflorescence characteristic of this group. Vanilla rivasii may be distinguished from the other Vanilla species in the group by the frequent terminal position of the inflorescence, although occasionally this can be lateral. The bracts of the inflorescence are smaller than those of related species such as $V$. cribbiana Soto-Arenas, V. ruiziana Klotzsch, and the sympatric $V$. dressleri Soto-Arenas. Flowers are larger, with deeply recurved sepals. The lateral sepals are fused in the basal third. The mid-lobe of the labellum is 
conspicuously bilobulated with a thickened axial cushion near the apex bearing 7-8 thickened veins with papilose texture extending into the lateral lobes. Vanilla rivasii is morphologically most similar to $V$. cribbiana but differs from this species in the fused lateral sepals in the basal third, the bi-lobed shape of the central lobe of the labellum and the greater number of thickened veins. Vanilla rivasii differs from the sympatric species $V$. dressleri in the tri-lobed labellum and non-granulose sepals. Additionally, the living flower of $V$. rivasii has much less conspicuous orange longitudinal stripes on the labellum than those of $V$. dressleri. Vanilla rivasii is more heliophytic than $V$. dressleri, with subcoriaceous, deep green, smooth leaves. It differs from $V$. ruiziana from Peru and Bolivia which has an ovate mid lobe of the lip, and 1-3 thickened veins on the lip apex. Vanilla rivasii plants have been documented with terminal inflorescences producing up to 150 flowers (less in lateral inflorescences), compared with a maximum recorded for $V$. hostmannii of 60 , and for $V$. cribbiana, and $V$. dressleri of ca. 10, and rarely up to 30 flowers. Mature fruits are dehiscent.
ACKNOWLEDGMENTS. We thank Nhora Helena Ospina Calderon for the line drawings; Álvaro Rivas for kindly sharing his knowledge and experience regarding vanillas; and the 'Semillero de Investigacion en Recursos Fitogeneticos' at the Universidad del Pacifico. Support for field trips was obtained from the research offices of the Pontificia Universidad Javeriana, Cali, the Universidad Nacional de Colombia, sede Palmira, (DIPAL), and the Vicerectoría de Investigación of Universidad Nacional de Colombia.

\section{LiterATURE CITED}

Faber-Langendoen, D., \& A.H. Gentry. 1991. The structure and diversity of rain forests at Bajo Calima, Choco Region, Western Colombia. Biotropica 23(1): 2-11.

Soto-Arenas, M.A. \& R.L. Dressler. 2010. A revision of the Mexican and Central American species of Vanilla Plumier ex Miller with a characterization of their ITS region of the nuclear ribosomal DNA. Lankesteriana 9(3): 285-354.

Soto-Arenas, M.A. 2010. A new species of Vanilla from South America. Lankesteriana 9(3): 281-284.

Soto-Arenas, M.A. \& P. Cribb. 2010. A new infrageneric classification and synopsis of the genus Vanilla Plum. ex Mill. (Orchidaceae: Vanillinae). Lankesteriana 9(3):355-398. 
